\title{
Obscure Cause of Upper Gastrointestinal Hemorrhage
}

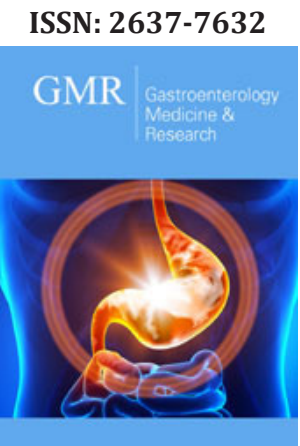

*Corresponding author: Johannes Koch, Clinical Professor, University of Washington Medical Center Department of Medicine, Division of Gastroenterology, USA

Submission: 僵 September 01, 2020

Published: 想September 11, 2020

Volume 5 - Issue 2

How to cite this article: Johannes Koch, Alison Lytle Perrin, Deepti Reddi. Obscure Cause of Upper Gastrointestinal Hemorrhage. Gastro Med Res. 5(2). GMR.000606. 2020.

DOI: $10.31031 /$ GMR.2020.05.000606

Copyright@ Johannes Koch, This article is distributed under the terms of the Creative Commons Attribution 4.0 International License, which permits unrestricted use and redistribution provided that the original author and source are credited.

\author{
Johannes Koch ${ }^{1 *}$, Alison Lytle Perrin ${ }^{2}$ and Deepti Reddi ${ }^{3}$ \\ ${ }^{1}$ Department of Medicine, Division of Gastroenterology, University of Washington Medical \\ Center, USA \\ ${ }^{2}$ Department of Surgery, University of Washington Medical Center, USA \\ ${ }^{3}$ Department of Laboratory Medicine and Pathology, University of Washington Medical Center, \\ USA
}

\begin{abstract}
A 31year-old man presented to an outside institution's emergency department with headache, vomiting and no signs of bleeding. With decreased hemoglobin (hgb) of $4.6 \mathrm{~g} / \mathrm{dl}$ and normal head computerized tomography (CT), he was discharged on iron supplement. He presented to our emergency department 3 weeks later with weakness, tachycardia, hypotension, hgb of $5 \mathrm{~g} / \mathrm{dl}$ and a positive fecal occult blood test. With a normal colonoscopy and CT enterography, the patient was discharged to receive biweekly transfusions, and later underwent an outpatient small bowel capsule. Two months later the patient presented with weakness with no overt signs of bleeding and hgb was $4.2 \mathrm{~g} / \mathrm{dl}$. Push enteroscopy identified a nearly circumferential mass in the proximal jejunum with stigmata of recent hemorrhage. Subsequently six months from the initial presentation, the patient underwent laparoscopic small bowel resection of a $7.3 \mathrm{~cm}$ friable mass. The histopathology confirmed the endoscopic biopsy findings of a benign lymph vascular proliferation, favoring lymphangioma and an adjacent mesenteric lymph node with marked sinusoidal lymphangiectasia. One week post-surgery, the patient reported feeling well with an increased hgb of $7.1 \mathrm{~g} / \mathrm{dl}$.
\end{abstract}

Keywords: IM: Small bowel capsule;Push enteroscopy;Lymphangioma

\section{Introduction}

Obscure causes of gastrointestinal bleeding pose a diagnostic challenge to the physician and also can cause delay in diagnosis. When the source of bleeding is not identified by upper and lower gastrointestinal tract endoscopic evaluation, then only the small bowel becomes the focus of investigation. Here, we present a case of jejunal lymphangioma diagnosed by push enteroscopy/endoscopy.

\section{Case Presentation}

The patient is a 31 year-old second generation Korean American male with past medical history of attention deficit disorder, anxiety, Vitamin D deficiency, and obstructive sleep apnea, presented to an outside emergency department with headache, vomiting and no signs of bleeding. With hemoglobin (hgb) of $4.6 \mathrm{~g} / \mathrm{dl}$ and normal head computerized tomography (CT), he was discharged on iron supplement. He presented to our emergency department 3 weeks later with weakness, tachycardia, hypotension, hgb of $5 \mathrm{~g} / \mathrm{dl}$ and positive fecal occult blood test. A month later with hemoglobin $7.9 \mathrm{~g} / \mathrm{dl}$, normal colonoscopy and CT enterography, the patient was discharged to receive biweekly transfusions. At the main campus, as an outpatient procedure the patient underwent small bowel capsule with delay in scheduling and interpretation amidst the COVID-19 crisis. Two months later the patient represented with weakness but no overt signs of bleeding with hgb of $4.2 \mathrm{~g} / \mathrm{dl}$. Push enteroscopy identified a nearly circumferential mass in the proximal jejunum with stigmata of recent bleeding (Figure 1a). The parallel evaluation of the capsule study confirmed a bleeding lesion in the proximal small bowel corresponding to the endoscopy image. Subsequently six months from the initial presentation, the patient underwent laparoscopic small bowel resection showing a $7.3 \mathrm{~cm}$ friable mass (Figure 1b). Histopathology confirmed the endoscopic biopsy findings of benign lymph vascular proliferation, favoring lymphangioma (Figure 1c), with focal thrombus and a mesenteric lymph node with marked sinusoidal lymphangiectasia (Figure 1d). One week post-surgery, the patient was well with an increased hgb of $7.1 \mathrm{~g} / \mathrm{dl}$. 


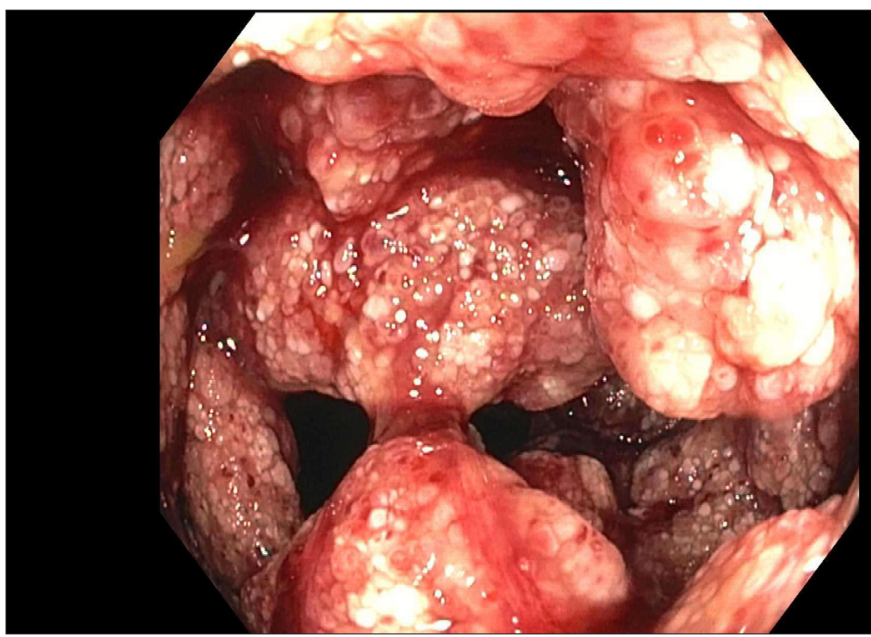

Figure 1a: Push enteroscopy/endoscopy showing a large fungating mass found in the proximal jejunum.

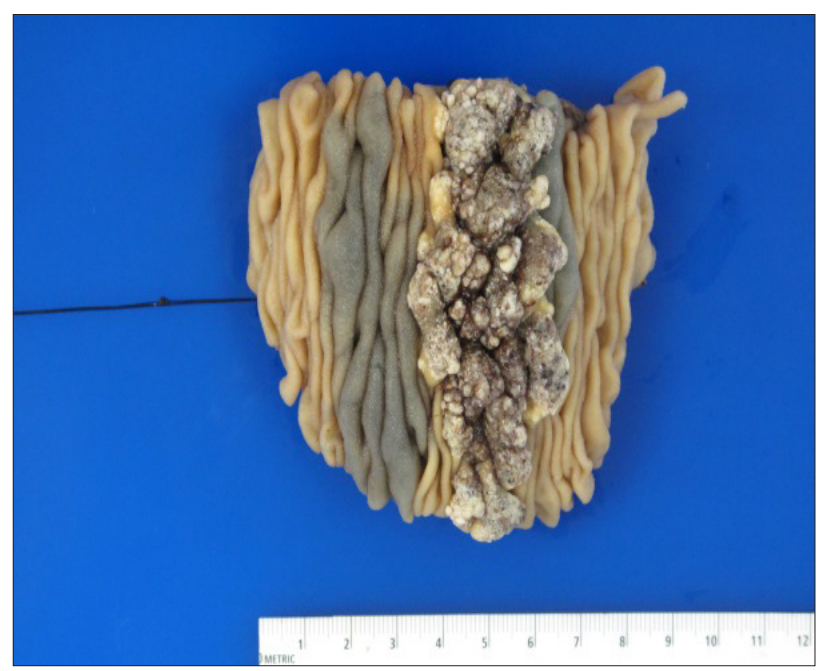

Figure 1b: By gross evaluation, $7.3 \times 3.0 \mathrm{~cm}$ tanred polypoid soft friable mass.

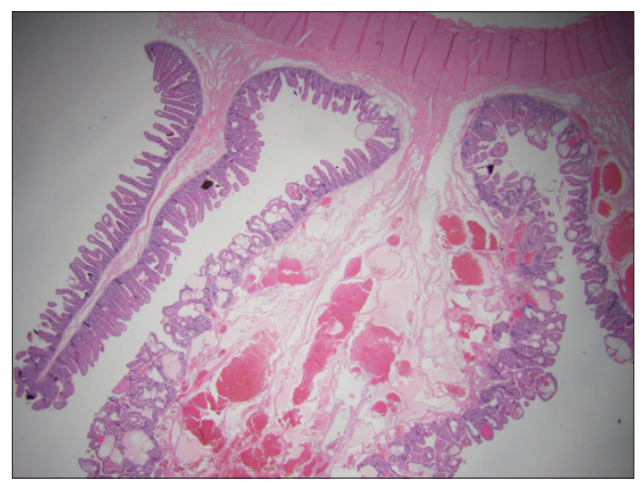

Figure 1c: By histology, a benign proliferation of lymphatic and vascular channels, primarily involving the mucosa and submucosa, but also extending into muscularis propria. (H\&E, 200x magnification).

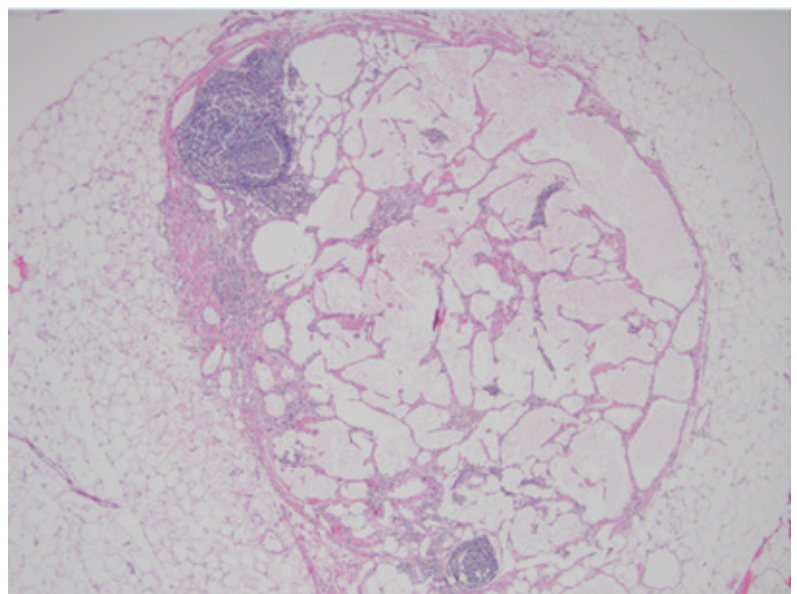

Figure 1d: One lymph node exhibits marked sinusoidal and perinodal lymphangiectasia. (H\&E, 400x magnification).

\section{Discussion}

From literature search, this is a rare case of jejunal lymphangioma diagnosed by push enteroscopy/endoscopy. There are several prior reports of jejunal lymphangioma mostly diagnosed by double-balloon enteroscopy and Sonde endoscopy [1-3]. Our case highlights the role of push enteroscopy/endoscopy for the diagnosis of proximal jejunal lesions that can lead to significant small-bowel bleeding, protein-losing enteropathy and intussusception.

\section{Conflicts of Interest}

The authors have no conflict of interest and no financial disclosure.

\section{References}

1. Hsu SJ, Chang YT, Chang MC, Yu SC, Lee JC, et al. (2007) Bleeding jejunal lymphangioma diagnosed by double balloon enteroscopy. Endoscopy 39: E5-E6.

2. Barquist ES, Apple SK, Jensen DM, Ashley SW (1997) Jejunal lymphangioma. An unusual cause of chronic gastrointestinal bleeding. Dig Dis Sci 42(6): 1179-1183.

3. Soontornmanokul T, Angsuwatcharakorn $\mathrm{P}$, Viriyautsahakul V, Rerknimitr R, Pantongrag-Brown L, et al. (2012) Jejunal lymphangioma: Rare case of GI bleeding. Gastrointest Endosc 76(4): 884-886. 